\title{
Refugee and Migrant Health Strategy for the Eastern Mediterranean Region
}

Ahmed Al-Mandhari, ${ }^{1}$ Ali Ardalan, ${ }^{1}$ Awad Mataria, ${ }^{1}$ Tonia Rifaey ${ }^{1}$ and Rana Hajjeh ${ }^{1}$

'World Health Organization Regional Office for the Eastern Mediterranean, Cairo, Egypt. (Correspondence to: Ali Ardalan: ardalana@who.int).

Citation: Al-Mandhari A; Ardalan A; Mataria A; Rifaey T; Hajjeh R. Refugee and Migrant Health Strategy for the Eastern Mediterranean Region. East Mediterr Health J. 2021;27(12):1129-1131 https://doi.org/10.26719/2021.27.12.1129

Copyright (C) World Health Organization (WHO) 2021. Open Access. Some rights reserved. This work is available under the CC BY-NC-SA 3.0 IGO license (https://creativecommons.org/licenses/by-nc-sa/3.o/igo).

The Eastern Mediterranean Region (EMR) is the origin and host to an increasing number of forcibly displaced people, mainly due to conflicts and economic disparities. Overall, $66 \%$ of the world's refugees originate from EMR. The numbers of internally displaced persons (IDPs) have been growing steadily in the region during the past decades, rising to 19.5 million in $2020,45 \%$ of the world's total. Some 11.7 million of these (including 5.7 million Palestinians) remain in the region $(1,2)$ while the rest have taken the risk of difficult journeys to countries outside of the region in search of asylum and better life. These populations are often at higher risk of poor health due to the conditions they live in and limited access to quality health care.

Labour migration is another key feature of the Region, which is an opportunity for regional development and growth. In 2020, 47.2 million people migrated across EMR borders (3), of whom 22 million stayed within the countries of the Region (4). While labour migrants often enjoy improved livelihoods, they may find themselves in vulnerable situations with possible human rights violations. The situation is more complicated for irregular migrants, who are difficult to identify, monitor and include in national health programmes and financial protection schemes. The COVID-19 pandemic confirmed the importance of inclusion of refugees and migrants in all national health policies and plans, for better preparedness and timely response $(5,6,7)$. COVID-19 knows no borders, and as long as there is active transmission anywhere there will be a risk of transmission everywhere (8).

Lack of disaggregated data on the health of refugees and migrants is a key challenge for policymaking. Selected studies have investigated disparities in the health status and access to health care among refugees and migrants and host populations. Maternal Mortality Ratio among Syrian refugee women in Lebanon was found to be higher than that of Lebanese women: 55.1 vs. 10.0 per 100000 live births in 2017 (9). A nationally representative multi-indicator cluster survey among Palestinians found antenatal care coverage to be lower for refugees than non-refugees (88.2 vs. 95.9\%) (10). A study found that $20 \%$ of Syrian patients with breast cancer presented with distant metastasis, compared with only $16 \%$ among Jordanians seen during the same period (11). Refugees presented higher prevalence of Post-Traumatic Stress Disorder (PTSD) than the normal population $(6.0-81.0 \%$ vs. $6.1-9.2 \%)(12)$. Another study conducted in Lebanon showed that refugees are less likely to test for HIV than nationals ( $46 \%$ vs. $62 \%$ ) (13).

Inadequate financing and lack of insurance coverage are among the main challenges in the provision of timely and quality services to refugees and migrants. According to the United Nations, $86 \%$ of Syrian refugees outside camps in Jordan live below the poverty line. In refugee camps, essential services have been maintained and safety measures established while urban refugees and host communities struggle to access basic services and earn an income (14). A report by the United Nations Relief and Works Agency for Palestine Refugees (UNRWA) in 2020 demonstrates that an estimated 60\% of Palestinian refugees in Jordan did not have money to buy their medications, especially because the livelihood of the majority was disrupted during the COVID-19 pandemic (15). Another study reported that almost $42 \%$ of ex-Gazan families living in Jerash camp in Jordan suffered from catastrophic health expenses (16). During the COVID-19 pandemic, some Gulf Cooperation Council (GCC) governments such as Saudi Arabia and United Arab Emirates (UAE) offered free treatment to all residents, regardless of their migration status, including undocumented migrants. A study in Saudi Arabia found that around one third of labour migrants were either uninsured or not yet enrolled in a health insurance scheme (17).

Migration of health workforce is another aspect of migration health in our region. Despite the huge needs in the region the number of doctors and nurses migrating to other countries is increasing. Seventeen percent of nurses and $20 \%$ of doctors have left Lebanon during recent crises. The total annual cost of physician emigration in the EMR is US\$ 3468 million, i.e. $0.205 \%$ (0.036\% to $0.0503 \%$ ) of the gross national income. Pakistan is among the four countries worldwide that has the highest total costs (18).

EMR Vision 2023 calls for solidarity and action to promote "Health for All by All", including in relation to refugees, migrants and displaced people (19). The Regional Health Alliance has facilitated our work with health partners, ensuring harmonized strategies and approaches (20). This partnership is needed more than ever. To guide regional efforts, the World Health Organization Eastern Mediterranean Regional Office (WHO EMRO) drafted an EMR strategy for the health of refugees and migrants, based on the global action plan, 2019-2023, on promoting the health of refugees and migrants (21), while accounting 
for regional specificities and priorities. The draft strategy was presented and discussed during the 68th session of the regional committee in 2021.

The strategy aims to improve the health and well-being of refugees and migrants in an inclusive and comprehensive manner and as part of holistic efforts to respond to the health needs of the overall population. This goal will be realized through four strategic objectives:

- Mainstream refugees and migrants into national health policies, strategies and plans, focusing on inclusion into service delivery and financing strategies and integration into surveillance and routine health information systems (22).

- Respond timely and effectively to the needs of refugees and migrants in emergency situations, ensuring access to a continuum of care during influx and humanitarian crises using an all-hazard, whole-of-government and whole-of-society approaches, in line with international treaties and conventions (23).

- Improve social determinants of health and wellbeing of refugees and migrants alongside that of host communities. This can only be done by ensuring that health protection programmes guarantee refugees and migrants with similar protection as for nationals, including for occupational safety, while leveraging community engagement to improve risk communication and social mobilization and outreach (24).

- Strengthen partnership as a collective responsibility by Member States, United Nations agencies, donors and civil society organizations. This is particularly important because of the multi-sectoral nature of the health agenda for refugees and migrants.

It is worth noting that the entitlements of refugees and migrants, including access to health services, vary by country, depending on national laws. As such, implementation should consider specific country situations and should be in accordance with national legislations, priorities, and circumstances, as well as international instruments $(25,26)$. Moving forward in implementing the draft regional strategy requires the following actions by Member States and all partners:

- Develop a strategy to include the health of refugees and migrants in national policies and plans.

- Strengthen migration health programmes at national and local levels and improve multisectoral collaboration.

- Integrate migration health related variables into health information systems and surveys.

- Ensure continuity of essential health services during normal conditions and emergencies.

- Build institutional capacities to support research on the health of refugees and migrants.

WHO remains committed to working with all Member States and partners to ensure the development and implementation of refugees- and migrants-sensitive health policies. Existing initiatives and good regional practices constitute a platform to ensure implementation of the above priority actions. Examples include, but not limited to, setting up a migration health desk by Sudan Ministry of Health; establishing an insurance scheme for refugees in the Islamic Republic of Iran; inclusion of refugees and migrants in the national health plans of Jordan, Morocco and Tunisia; supporting displaced populations from neighboring conflict-affected countries by Jordan, Lebanon and Oman; and inclusion of migrants in COVID-19 pandemic response and vaccination programmes by GCC countries.

The current EMHJ special edition is an attempt to encourage research in support of evidence-based policymaking and planning in the context of refugees and migrants health in EMR. The special edition specifically addresses the following themes: universal health coverage and inclusion in national health systems, social determinants of the health of refugees and migrants, and preparedness for and response to the COVID-19 pandemic.

\section{References}

1. IOM Displacement Tracking Matrix. Available: https://dtm.iom.int/. Accessed: 23 December 2021.

2. UNHCR operational data portal. Available: https://data2.unhcr.org/en/situations. Accessed: 23 December 2021.

3. United Nations. International Migrant Stock. Available: https://www.un.org/development/desa/pd/content/international-migrant-stock. Accessed: 23 December 2021.

4. Estimate of 2019 (Situation report on international migration 2019: The Global Compact for Safe, Orderly and Regular Migration in the context of the Arab region. Beirut: United Nations Economic and Social Commission for West Asia and International Organization for Migration; 2019 (https://undocs.org/pdf?symbol=en/E/ESCWA/SDD/2019/3, accessed 5 April 2020).

5. World Health Organization Regional Office for the Eastern Mediterranean (WHO/EMRO). WHO interim guidance: Health system response to COVID-19 in the context of internally displaced persons, refugees, migrants and returnees in the Eastern Mediterranean Region. Cairo: WHO/EMRO; 2020

6. Mowafi H; Sakr H; Ravaghi H; Elmahal O; Slama S; Samhouri D; et al. Leveraging the COVID-19 response to improve emergency care systems in the Eastern Mediterranean Region. East Mediterr Health J. 2020;26(6):626-629 https://doi. $\operatorname{org} / 10.26719 / 2020.26 .6 .626$

7. Matsumoto M; Wimer G; Sethi A. Health needs of refugees: port of arrival versus permanent camp settings. East Mediterr Health J. 2019;25(5):306-314 https://doi.org/10.26719/emhj.18.041 
8. World Health Organization. COVID-19 immunization in refugees and migrants: principles and key considerations: interim guidance. Available: https://www.who.int/publications/i/item/covid-19-immunization-in-refugees-and-migrants-prinm ciples-and-key-considerations-interim-guidance-31-august-2021 . Accessed: 23 December 2021.

9. Faysal El Kak, Hilda Harb, Sirine Daouk, Anwar Nassar, Tamar Kabakian-Khasholian. Maternal mortality in Lebanon: Increased vulnerability among Syrian refugees. Published: 09 December 2021. https://doi.org/10.1002/ijgo.14063

10. UNICEF. Palestinian Multiple Indicator Cluster Survey 2019-2020. 2021.

11. Mansour A, Al-Omari A, Sultan I. Burden of Cancer Among Syrian Refugees in Jordan. J Glob Oncol. 2018; 4: JGO.18.00132. Published online 2018 Oct 11. doi: 10.1200/JGO.18.00132.

12. Sareen J. Posttraumatic stress disorder in adults: Epidemiology, pathophysiology, clinical manifestations, course, assessment, and diagnosis. 2018. Available: https://www.uptodate.com/contents/posttraumatic-stress-disorder-in-adults-epidemiology-pathophysiology-clinical-manifestations-course-assessment-and-diagnosis.

13. Tohme J, Egan JE, Stall R, Wagner G, Mokhbat J. HIV Prevalence and Demographic Determinants of Unprotected Anal Sex and HIV Testing among Male Refugees Who have Sex with Men in Beirut, Lebanon. AIDS Behav. 2016;20:408-16.

14. European Commission. European Civil Protection and Humanitarian Aid Operations. https://reliefweb.int/sites/reliefweb.int/ files/resources/jordan_2020-02-07.pdf. Last updated 31/03/2021.

15. United Nations Relief Agency. Rapid socio-economic study of the effects of covid-19 on Palestine refugees in jordan. 2020.

16. Abdo N, Abu Naqera K, Batieha A, Abu Zayed I. Catastrophic health expenditure among ex-Gazan families in Jerash camp, Jordan. Public Health. 2020;186:101-6.

17. Bdulwahab A, Cosgrove P, Mohamed G, Hassan A. The personal and workplace characteristics of uninsured expatriate males in Saudi Arabia. BMC Health Services Research. 2017;17(56):(19 January 2017).

18. Saurabh Saluja, Niclas Rudolfson, Benjamin Ballard Massenburg, John G Meara, Mark G Shrime. The impact of physician migration on mortality in low and middle-income countries: an economic modelling study. BMJ Glob Health. 2020; 5(1): eoo1535. doi: 10.1136/bmjgh-2019-001535.

19. Al-Mandhari A. Achieving "Health for All by All" in the Eastern Mediterranean Region. East Mediterr Health J. 2019 Oct 13;25(9):595-596. https://doi.org/10.26719/2019.25.9.595.

20. World Health Organization Regional Office for the Eastern Mediterranean (WHO/EMRO). Regional health alliance. Available: http://www.emro.who.int/health-topics/regional-health-alliance/index.html. Accessed: 23 December 2021.

21. World Health Organization. Promoting the health of refugees and migrants: draft global action plan, 2019-2023. Geneva: 2019. Available: https://apps.who.int/iris/handle/10665/328690. Accessed: 23 December 2021.

22. Mataria A; Brennan R; Rashidian A; Hutin Y; Hammerich A; El-Adawy M; et al. 'Health for All by All' during a pandemic: 'Protect Everyone' and 'Keep the Promise' of Universal Health Coverage in the Eastern Mediterranean Region. East Mediterr Health J. 2020;26(12):1436-1439. https://doi. org/10.26719/2020.26.12.1436

23. Brennan R, Hajjeh R, Al-Mandhari A. Responding to health emergencies in the Eastern Mediterranean region in times of conflict. Lancet 2020(2 March). https://doi.org/10.1016/S0140-6736(20)30069-6 (Epub ahead of print).

24. Commission on Social Determinants of Health in the Eastern Mediterranean Region. Build back fairer: achieving health equity in the Eastern Mediterranean Region: report of the Commission on Social Determinants of Health in the Eastern Mediterranean Region - executive summary. Cairo: WHO Regional Office for the Eastern Mediterranean; 2021. License: CC BY-NC-SA 3.0 IGO.

25. Seventieth World health Assembly, Geneva, 31 May 2017, Agenda item 13.7, WHA 70.15, Promoting the health of refugees and migrants. Available: http://apps.who.int/gb/ebwha/pdf_files/WHA70/A70_R15-en.pdf. Accessed: 23 December 2021.

26. World Health Organization. Promoting the health of refugees and migrants: draft global action plan, 2019-2023. Geneva: 2019. Available: https://apps.who.int/iris/handle/10665/328690. Accessed: 23 December 2021. 